\title{
EDITORIAL
}

\section{How to train a future urogynecologist}

\author{
Tamara Serdinšek ${ }^{1}$
}

Received: 27 September 2021 / Accepted: 28 September 2021 / Published online: 12 November 2021

(c) The International Urogynecological Association 2021

Pelvic floor disorders (PFDs) comprise a wide spectrum of bothersome conditions such as urinary incontinence (UI), fecal incontinence (FI), and pelvic organ prolapse (POP). These disorders are highly prevalent in women, and it has been estimated that almost every fourth woman in the USA is affected. It has been established by $\mathrm{Wu}$ et al. that the proportion of women with one or more PFDs substantially increases with increased age, which is why it has been proposed that the aging of the population and the obesity epidemic will lead to an increased number of affected women [1]. Moreover, some increase in demand for care for women with PFD will possibly also be the consequence of increased awareness among physicians about this topic and among patients owing to online resources [2]. According to some projections, the number of women with at least one PFD in the USA will increase from 28.1 million in 2010 to 43.8 million in 2050. During this time, the number of women with $\mathrm{UI}$ is supposed to increase by $55 \%$, the number of women with FI by $59 \%$, and the number of women with POP by $46 \%$ [3]. As such, PFDs will represent an important public health issue with lives of millions of adult women being negatively impacted [4]. PFDs are becoming a significant burden in terms of reduced quality of life and workforce productivity. Moreover, both direct and indirect costs will increase. In the USA, each year, approximately 80,000 procedures are performed because of UI, 220,000 because of POP, and 3,500 because of FI. These numbers will most likely increase, as well as costs owing to behavioral therapy, physiotherapy, pharmacological treatment, etc. [3]. It has been estimated that the surgical rates for SUI or POP will increase by $42.7 \%$ and that the demand for care for PFD will increase up to $35 \%$ from 2010 to $2030[2,4]$.

But is our society prepared for such an epidemic of PFD? Wu et al. have already emphasized that we need to ensure

Tamara Serdinšek

todorovic.tamara@gmail.com

1 Department for General Gynecology and Urogynecology, Clinic for Gynecology and Perinatology, University Medical Centre Maribor, Ljubljanska 5, 2000 Maribor, Slovenia that there are enough specifically trained providers to care for these women and to develop efficient preventive and therapeutic measures of PFD, which will help to reduce the estimated public health burden in the future [3]. As not all general gynecologists are trained in providing comprehensive PFD treatment, the most of this burden will increasingly fall on subspeciality trained providers, meaning that we may need to increase the number of these providers [2], including the number of trained urogynecologists.

Urogynecology or female pelvic medicine and reconstructive surgery (FPMRS) has been recognized as an accredited subspecialty in some countries [5]. In others, the only knowledge and skills that young gynecologists have in this field are obtained during their general residency training. In the USA, female pelvic medicine and reconstructive surgery became an accredited subspecialty as late as 2013. Since then, the number of residency programs in this field and the percentage of total graduates accepted into the program have increased. However, these numbers are still low compared with other subspecialties. For example, the number of resident graduates enrolling in maternal-fetal medicine fellowships in 2012 was approximately twice that of the other gynecological subspecialty programs [5]. At this rate, it is questionable whether we will be able to educate enough subspecialists in this field to cover all the needs. Besides increasing the number of people enrolling in subspeciality programs, one of the solutions could also be to transfer a part of this increased workload to general gynecologists. However, how comfortable and trained are general gynecologists when dealing with urogynecological patients? An internet-based survey, published in 2007, included 205 third and fourth-year residents discovered that $46 \%$ of them were unsatisfied with urogynecology education during residency. Furthermore, FPMRS fellows were involved in the education of only $23.9 \%$ respondents. Most respondents felt comfortable performing anterior and posterior repair, McCall's culdoplasty, and cystoscopy [6]. A survey amongst fellowship program directors from 2015 concluded that residents might be underprepared for advanced subspecialty training, as only $20 \%$ of first-year fellows were 
able to independently perform a vaginal hysterectomy, $46 \%$ abdominal hysterectomy, and $34 \%$ basic hysteroscopic procedures [7]. On the contrary, residents rated their preparedness higher than program directors and $74.5 \%$ of FPMRS respondents reported feeling "prepared" or "very prepared" for the subspecialty training [8].

The question how to train (enough) future urogynecologists remains. When FPMRS fellows were asked about the reasons for choosing this subspecialty, the most frequent answers were the ability to do clinical medicine and perform surgery, the complexity of surgical cases, the amount of time spent in the operating room, and interest in the treatment of diseases of the bladder, bowel, and pelvic floor. Moreover, they felt that when compared with other subspecialties, FPMRS was associated with more new developments and techniques, higher satisfaction rate, higher number of procedures, and more research potential. Moreover, they felt that there was more encouragement to join the field, but also more competition for entry [9]. In order to find residents who are interested in urogynecology, we should provide early exposure to both clinical and research work in this field. The national residency programs need to be updated and should include appropriate amounts of urogynecology rotation. As urogynecological procedures, especially laparoscopic procedures, are very complex, the inclusion of obligatory simulation training would probably be beneficial. And in the end, even more importantly, national stakeholders will have to prepare projections and plans on how to provide not just enough urogynecologists but also other specifically trained providers and the necessary infrastructure to meet the demands of the increasing number of patients.

Acknowledgements Dedicated to my boss, who is my greatest teacher and mentor.

\section{Declarations}

Conflicts of interest None.

\section{References}

1. Wu JM, Vaughan CP, Goode PS, Redden DT, Burgio KL, Richter HE, et al. Prevalence and trends of symptomatic pelvic floor disorders in U.S. women. Obstet Gynecol. 2014;123(1):141-8.

2. Kirby AC, Luber KM, Menefee SA. An update on the current and future demand for care of pelvic floor disorders in the United States. Am J Obstet Gynecol. 2013;209(6):584.e1-5.

3. Wu JM, Hundley AF, Fulton RG, Myers ER. Forecasting the prevalence of pelvic floor disorders in U.S. women: 2010 to 2050. Obstet Gynecol. 2009;114(6):1278-83.

4. Dieter AA, Wilkins MF, Wu JM. Epidemiological trends and future care needs for pelvic floor disorders. Curr Opin Obstet Gynecol. 2015;27(5):380-4.

5. Rayburn WF, Gant NF, Gilstrap LC, Elwell EC, Williams SB. Pursuit of accredited subspecialties by graduating residents in obstetrics and gynecology, 2000-2012. Obstet Gynecol. 2012;120(3):619-25.

6. Schimpf MO, Feldman DM, O'Sullivan DM, LaSala CA. Resident education and training in urogynecology and pelvic reconstructive surgery: a survey. Int Urogynecol J Pelvic Floor Dysfunct. 2007;18(6):613-7.

7. Guntupalli SR, Doo DW, Guy M, Sheeder J, Omurtag K, Kondapalli L, et al. Preparedness of obstetrics and gynecology residents for fellowship training. Obstet Gynecol. 2015;126(3):559-68.

8. Urban RR, Ramzan AA, Doo DW, Galan HL, Harper L, Omurtag $\mathrm{K}$, et al. Fellow perceptions of residency training in obstetrics and gynecology. J Surg Educ. 2019;76(1):93-8.

9. Siddighi S, Barker M, Pancholy A, Krallman K, Karram MM, Kleeman S. Attitudes and perceptions regarding subspecialty training in female pelvic medicine and reconstructive surgery. Int Urogynecol J Pelvic Floor Dysfunct. 2008;19(11):1523-6.

Publisher's note Springer Nature remains neutral with regard to jurisdictional claims in published maps and institutional affiliations. 